\title{
Potential linkage between sedimentary oxygen consumption and benthic flux of biogenic elements in a coastal scallop farming area, North Yellow Sea
}

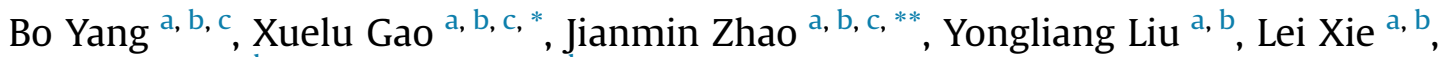 \\ Xiaoqing Lv ${ }^{\text {a, b }}$, Qianguo Xing a, b, c \\ ${ }^{a}$ CAS Key Laboratory of Coastal Zone Environmental Processes and Ecological Remediation, Yantai Institute of Coastal Zone Research, Chinese Academy of \\ Sciences, Yantai, Shandong, 264003, China \\ ${ }^{\mathrm{b}}$ University of Chinese Academy of Sciences, Beijing, 100049, China \\ c Center for Ocean Mega-Science, Chinese Academy of Sciences, Qingdao, Shandong, 266071, China
}

\section{H I G H L I G H T S}

- Benthic release of biogenic elements was explored by static incubation experiments.

- Variations in their interface fluxes with dissolved oxygen were evaluated.

- Potential influence of scallop farming on their benthic release was analyzed.

- Sediment served as a key source of biogenic elements for overlyingwater ecosystem.

\section{A R T I C L E I N F O}

\section{Article history:}

Received 28 October 2020

Received in revised form

8 January 2021

Accepted 12 January 2021

Available online 13 January 2021

Handling Editor: Michael Bank

\section{Keywords:}

Mariculture area

Surface sediment

Laboratory incubation

Coastal biogeochemistry

Water-sediment interface

\section{G R A P H I C A L A B S T R A C T}

\begin{abstract}
A B S T R A C T
Surface sediments were collected from a mariculture area adjacent to the Yangma Island suffering from hypoxia in summer, and a laboratory static incubation was conducted to study the sedimentary oxygen consumption (SOC) and the benthic fluxes of nutrients and fluorescent dissolved organic matter (FDOM). Compared with some coastal areas, the SOC of the studied area was relatively low in summer with the value of $2.34-6.03 \mathrm{mmol} \mathrm{m}^{-2} \mathrm{~d}^{-1}$. Sediment acted as an important source of nutrients (except for nitrate) and FDOM for the overlying water. Dissolved oxygen (DO) in the overlying water could affect the decomposition mode of sedimentary organic matter (SOM), i.e. aerobic and anaerobic decomposi-

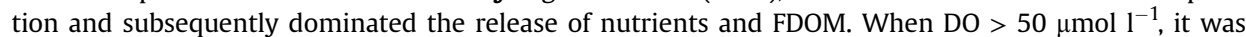
beneficial to the release of ammonium, silicate and FDOM. In contrast, low oxygen conditions, i.e. $\mathrm{DO}<100 \mu \mathrm{mol}^{-1}$, stimulated sediment phosphate efflux. In addition, scallop farming activities also affected the SOC and benthic flux of nutrients and FDOM mainly through biological deposition.
\end{abstract}

๑) 2021 Elsevier Ltd. All rights reserved.

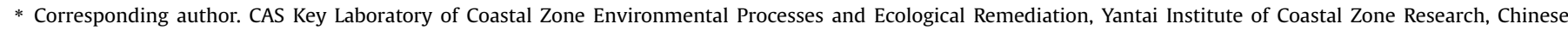
Academy of Sciences, Yantai, Shandong, 264003, China.

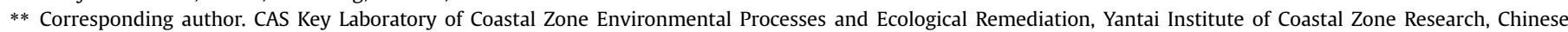
Academy of Sciences, Yantai, Shandong, 264003, China.

E-mail addresses: xlgao@yic.ac.cn (X. Gao),jmzhao@yic.ac.cn (J. Zhao).
} 


\section{Introduction}

Shellfish aquaculture is one of the fastest growing sectors of the food industry (FAO, 2016). While meeting human needs for food, excessive shellfish farming in recent years has a remarkable ecoenvironmental impact on coastal waters, e.g. the occurrence of water hypoxia (Lee et al., 2016) and transformation of carbon, nitrogen, phosphorus and silicon metabolism (Daniele et al., 2006; Valérie et al., 2007; Xia et al., 2019).

As one of the important processes, the biogeochemical cycle of sedimentary biogenic elements under the influence of shellfish farming has attracted widespread attention in recent years (Lee et al., 2016; Huang et al., 2018). The increased sedimentary organic matter (SOM) affected by shellfish farming activities has been shown to significantly increase sediment oxygen consumption (SOC) and the turnover of nutrients (Matos et al., 2016). These regenerated nutrients play an important role in phytoplankton production and could meet up to $100 \%$ of phytoplankton demand in some coastal waters (Van Broekhoven et al., 2014; Foster and Fulweiler, 2019; Kim et al., 2020). The biogeochemistry of SOM is mainly mediated by bacteria and depends on complex physicochemical and biological diagenetic processes (e.g. aerobic and anaerobic respiration), which is affected by many factors, e.g. redox characteristics, temperature and hydrodynamic conditions.

It is well known that temperature increase can significantly promote the metabolic rate of sediment microorganisms, thereby accelerating the nutrient turnover in the ecosystem (Zhou et al., 2017). Dissolved oxygen (DO) level can affect the decomposition modes of organic matter (OM), i.e. aerobic and anaerobic decomposition, and subsequent oxidation reactions (Hantush, 2007; Zhou et al., 2017; Foster and Fulweiler, 2019). Generally, OM is mineralized to carbon dioxide $\left(\mathrm{CO}_{2}\right)$ through aerobic respiration under oxygen-rich environment, while it can be transformed into methane $\left(\mathrm{CH}_{4}\right)$ or low molecular weight OM instead of the $\mathrm{CO}_{2}$ via fermentation in anaerobic conditions. Generally, the above process will be accompanied by the release of dissolved organic matter (DOM) (Gan et al., 2020); however, the characteristic and flux magnitude of this portion of DOM in different environments are presently unknown.

Furthermore, organic nitrogen (ON) can be converted to ammonium $\left(\mathrm{NH}_{4}^{+}\right)$through ammoniating under low oxygen condition (Gao, 2019). Meanwhile, nitrate $\left(\mathrm{NO}_{3}^{-}\right)$in anaerobic environments can be removed through the denitrification process (Rysgaard et al., 2004; Matos et al., 2016; Foster and Fulweiler, 2019). It is widely believed that DO is one of the most important parameters controlling the biogeochemical cycle of phosphorus (P) in aquatic ecosystems, which is mainly driven by the iron-bound $\mathrm{P}$ (Fe-P) migration in sediments (Liu et al., 2020). Generally, oxygenrich conditions are favorable for the formation of $\mathrm{Fe}-\mathrm{P}$. In contrast, large amounts of $\mathrm{P}$ can be released back into water due to reductive dissolution of Fe/Mn oxides under hypoxic conditions. In addition, some sedimentary material can be dispersed by currents, which affects the release of nutrients from the sediment, mainly depending on hydrodynamic conditions at the site (Tang et al., 2020).

The coastal waters around the Yangma Island, an important mariculture zone in the North Yellow Sea, are located next to the north coastline of Shandong Peninsula. The area is significantly affected by scallop farming activities. For example, the SOM content in this area was significantly higher than that in the surrounding area (Yang et al., 2018). Bottom water hypoxia in summer was observed in this area; it generally started to develop in July, reached its maximum in August, and gradually disappeared in autumn (Yang and Gao, 2019). The alternating changes of DO concentration in the bottom water could significantly affect SOC and other diagenetic processes (Yang et al., 2018, 2020a). The trophic level of water in this area was characterized as oligotrophy, and the sediment was one of the important sources of nutrients for the overlying water (Yang et al., 2020a). In addition, previous results showed that aerobic microbial degradation of sinking biological particles could be an important source of fluorescent dissolved organic matter (FDOM) based on the correlation between apparent oxygen utilization (AOU) and FDOM, especially for humic-like components (Yang and Gao, 2019). To sum up, amounts and characteristics of nutrients and DOM are greatly influenced by the SOM biodegradation process in this area.

Although the degradation process of SOM in coastal waters has been extensively studied (Derrien et al., 2019; Liu and Peng, 2019), as far as we know, little is known about the response relationship between the overlying-water DO conditions switching from being oxic to hypoxic and the SOM degradation modes, as well as the accompanying migration and transformation processes of biogenic elements, e.g. nutrients and DOM. Information about these is crucial especially in coastal waters where the overlying-water DO level changes intensely and frequently due to the influence of human activities. Thus, the data set of DO, dissolved nutrients, i.e. dissolved inorganic phosphorus $\left(\mathrm{PO}_{4}^{3-}\right)$, nitrogen (DIN) and silicate $\left(\mathrm{SiO}_{3}^{2-}\right)$, and $\mathrm{FDOM}$ fluxes across the sediment-water interface determined by a sediment static incubation were provided in this study. The main objectives were: (1) to identify the relationship between the overlying-water DO conditions and the degradation modes of SOM in summer in the coastal waters around the Yangma Island, and (2) to clarify the benthic fluxes of nutrients and FDOM under different SOM degradation modes and their main influencing factors.

\section{Materials and methods}

\subsection{Study area}

The study area is one of the important scallop culturing areas in China (Fig. 1). Some small rivers run into the coastal water with the mean annual freshwater discharge of $89.5 \times 10^{6} \mathrm{~m}^{3} \mathrm{yr}^{-1}(0.7 \%$ of the water volume in this study area) (Yang et al., 2020a).

\subsection{Sample collection and storage}

The samples used in this research were collected in July 2017, which is a time period of frequent hypoxia in the study area. The top $\sim 2 \mathrm{~cm}$ sediments were gathered and frozen at $-20^{\circ} \mathrm{C}$ in a nitrogen environment for subsequent processing in the laboratory. Nevertheless, the storage conditions may alter the activity of native microorganisms and the composition of the microbial community, but these potential changes were not intensively studied and not taken into consideration in this research. The redox potential (ORP) in the sediment was measured in-situ using a potentiometer with an ORP composite electrode (Leici 501, China). The overlying water collection and analytical methods, including salinity, temperature, DO, DIN, $\mathrm{PO}_{4}^{3-}$ and $\mathrm{SiO}_{3}^{2-}$ can be seen from Yang et al. (2020a) (cf. Supplementary Information Section S1.1 for detail).

After arriving in the lab, the sediments were immediately put in an incubator set at $20^{\circ} \mathrm{C}$. A portion of each sample was used for subsequent incubation experiment. Another portion of each sample was freeze-dried for the subsequent analysis of grain-size, total organic carbon (OC) and nitrogen (TN).

\subsection{Incubation experiment}

To study SOC and the fluxes of dissolved nutrients and FDOM 


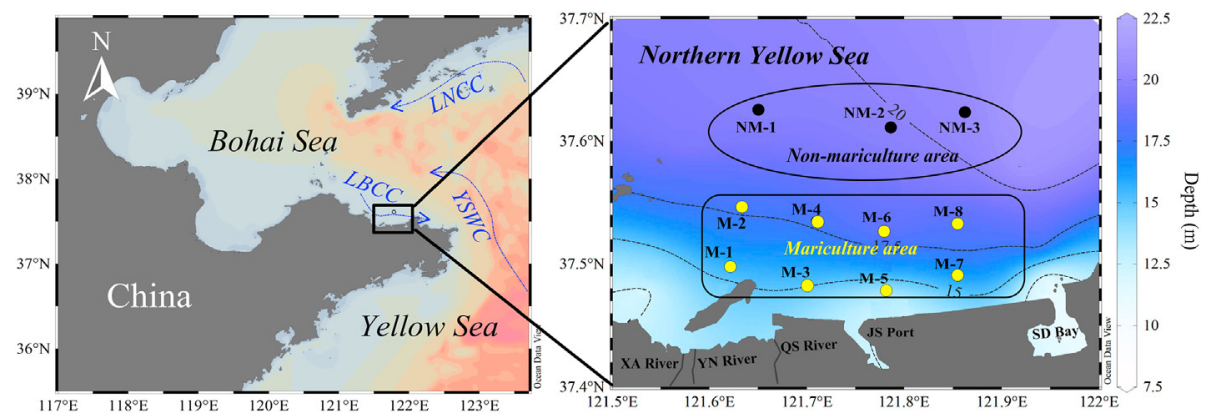

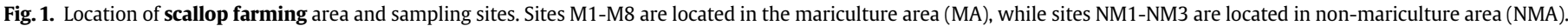

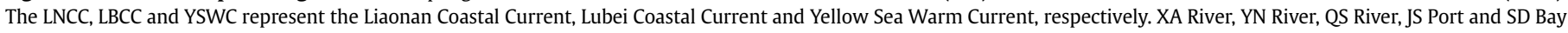

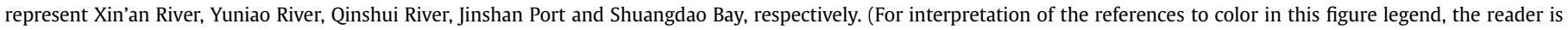
referred to the Web version of this article.)

across the sediment-water interface, the sediment samples from sites M1-M8 in the mariculture area (MA) and NM1-NM3 in the non-mariculture area (NMA) had been through static incubation for 11 days without aeration in lab under simulated field condition (Table S1) with artificial seawater (cf. Supplementary Information Section S1.2 for detail). For each sample, 500 g wet surface sediments were accurately weighed and placed in a 3-L airtight glass bottle and filled with artificial seawater. Subsequently, the incubation experiment was carried out in a biochemistry incubator under dark condition at $20{ }^{\circ} \mathrm{C}$. Timing was started after the experimental systems had been stabled for $2 \mathrm{~h}$, and $50 \mathrm{ml}$ water sample was drawn from each culture bottle after $0,24,48,72,96$, $120,144,168,192,216$ and $264 \mathrm{~h}$, respectively. In order to maintain a constant water volume, the same amount of artificial seawater was added back to each culture bottle after sampling.

\subsection{Analytical methods}

DO was determined using a portable DO analyzer (JPB-697A) in the laboratory immediately after sampling to minimize atmospheric exchange. Samples for nutrients and FDOM determinations were filtered through 0.45 and $0.2 \mu \mathrm{m}$ Millipore filters, respectively. $\mathrm{PO}_{4}^{3-}, \mathrm{SiO}_{3}^{2-}$ and $\mathrm{DIN}$, including $\mathrm{NH}_{4}^{+}$, nitrite $\left(\mathrm{NO}_{2}^{-}\right)$and $\mathrm{NO}_{3}^{-}$were measured using a SEAL Analytical autoanalyzer with the detection limits of $0.02 \mu \mathrm{mol} \mathrm{l}^{-1}$ for DIN and $\mathrm{SiO}_{3}^{2-}$ and $0.01 \mu \mathrm{mol} \mathrm{l}^{-1}$ for $\mathrm{PO}_{4}^{3-}$. FDOM was obtained using three dimensional excitation-emission matrix spectroscopy (EEMs), which was measured with a Hitachi F-7000 fluorescence spectrometer, combined with parallel factor analysis (PARAFAC) (Yang and Gao, 2019). The fluorescence intensity in all samples was calibrated in quinine sulfate units (QSU).

Dissolved inorganic carbon (DIC) was determined by infrared detection using a DIC analyzer (Apollo SciTech) (Cai et al., 2004). During the determination of DIC, certificated reference material (Batch 155) from A.G. Dickson's lab was used for quality assurance at a precision level of $\pm 2 \mu \mathrm{mol} \mathrm{l}^{-1}$.

For sediment, the OC and TN contents were analyzed with an Elementar vario MACRO cube CHNS analyzer, and the precision was $\pm 0.02 \%$ for OC and $\pm 0.003 \%$ for TN by dry weight $(n=5)$. Grain-size compositions were analyzed with a Mastersizer 2000 laser particle size analyzer (Yang et al., 2018). Generally, the particle sizes were classified as $<4,4-63$ and $>63 \mu \mathrm{m}$ for clay, silt and sand.

\subsection{Calculation of SOC and biogenic element release fluxes}

SOC ( $m m o l ~ \mathrm{~m}^{-2} \mathrm{~d}^{-1}$ ) was determined according to the batch incubation technique of Rysgaard et al. (2004) and Song et al. (2016), which was calculated based on the declining rate of DO concentration (the concentration after sea water volume correction, the same below) during the 11 day-incubation period. The calculation formula is as follows:

$\mathrm{SOC}=\left(k-k_{0}\right) \times V / S \times 24 / 1000$

where $k_{0}$ and $k\left(\mu \mathrm{mol} \mathrm{O} \mathrm{l}^{-1} \mathrm{~h}^{-1}\right)$ are the linear regression slopes of DO concentration versus time in the experimental control (artificial seawater without sediment) and sample groups (artificial seawater with sediment), respectively; $V$ is the volume of overlying water $(2.8 \mathrm{~L}) ; S$ is the sectional area of the culture bottles $\left(0.0143 \mathrm{~m}^{2}\right)$.

Similarly, the release fluxes of nutrients $\left(\mathrm{mmol} \mathrm{m}^{-2} \mathrm{~d}^{-1}\right.$ for $\mathrm{NH}_{4}^{+}$ and $\mathrm{SiO}_{3}^{2-}$, and $\mu \mathrm{mol} \mathrm{m}{ }^{-2} \mathrm{~d}^{-1}$ for $\mathrm{NO}_{3}^{-}$and $\mathrm{PO}_{4}^{3-}$ ), FDOM components (QSU $1 \mathrm{~m}^{-2} \mathrm{~d}^{-1}$ ) and DIC (mmol m $\mathrm{m}^{-2} \mathrm{~d}^{-1}$ ) were also calculated based on the above principles:

Flux $(i)=\left(k-k_{0}\right) \times V / S \times 24 / 1000$

where $i$ represents the target parameters in this study, i.e. nutrients, FDOM components and DIC; $k_{0}$ and $k\left(\mu \mathrm{mol} \mathrm{l}{ }^{-1} \mathrm{~h}^{-1}\right.$ for nutrients and DIC; QSU $\mathrm{h}^{-1}$ for FDOM components) are the linear regression slopes of the concentration of parameter $i$ versus time in the experimental control and sample groups, respectively; $V$ is the volume of overlying water $(2.8 \mathrm{~L}) ; \mathrm{S}$ is the sectional area of the culture bottles $\left(0.0143 \mathrm{~m}^{2}\right)$. The positive value of flux indicates the release of target element from sediment, while the negative value indicates the absorption of target element by sediment.

\section{Results}

\subsection{General characteristics of the overlying water and sediment}

For physico-chemical properties of the overlying water, their detailed information in the investigated sites has been previously reported (Yang and Gao, 2019; Yang et al., 2020a). During the investigation, the DO concentration varied broadly from 98.3 to $205.1 \mu \mathrm{mol} \mathrm{l}^{-1}$ (Table S1). The values of $\mathrm{NH}_{4}^{+}, \mathrm{NO}_{2}^{-}, \mathrm{NO}_{3}^{-}, \mathrm{PO}_{4}^{3-}$, and $\mathrm{SiO}_{3}^{2-}$ ranged from 1.22 to $6.98,0.09$ to $0.24,1.11$ to $6.89,0.24$ to 1.14 , and 2.38 to $5.38 \mu \mathrm{mol} \mathrm{l}^{-1}$, respectively (Table S1). In terms of FDOM, four components $(\mathrm{C} 1-\mathrm{C} 4)$ were identified. The components $\mathrm{C} 1 \mathrm{Ex} /$ $\mathrm{Em}=275 / 325 \mathrm{~nm}), \mathrm{C} 2(\mathrm{Ex} / \mathrm{Em}=250,310 / 380 \mathrm{~nm}), \mathrm{C} 3(\mathrm{Ex} /$ $\mathrm{Em}=270,360 / 450 \mathrm{~nm})$ and $\mathrm{C} 4(\mathrm{Ex} / \mathrm{Em}=285 / 335 \mathrm{~nm})$ were similar to marine protein-like or tryptophan-like, marine humic-like, humic-like and tryptophan-like substances (Fig. S1) (Yang and Gao, 2019), and their corresponding fluorescence intensities were $0.206-0.545,0.228-0.306,0.172-0.233$ and $0.020-0.052$ QSU, respectively (Table $\mathrm{S} 1$ ). 
In terms of the sediment samples, the median grain-size $\left(D_{50}\right)$ varied from 10.5 to $33.8 \mu \mathrm{m}$. Overall, fine-grained particles (silt and clay components) were the dominant fractions at most sampling stations (except site M3) accounting for $~ 80 \%$ of grain-size compositions (Table S2). OC and TN ranged from 0.34 to $0.84 \%$ (mean $0.66 \pm 0.17 \%$ ), and 0.43 to $1.02 \%$ (mean $0.83 \pm 0.19 \%$ ) with the high values being observed in the samples from the MA (Table S2).

\subsection{SOM degradation characteristics}

Fig. 2 shows the changing characteristics of DO and DIC concentrations during the incubation experiment on the samples from the MA and the NMA. In general, the DO concentration decreased steadily in the first $96 \mathrm{~h}$, after which the decreasing rates of DO slowed, dropping to below $50 \mu \mathrm{mol} \mathrm{l}^{-1}$ after the 192nd hour (Fig. 2a and b). For DIC, its concentration increased slowly in the first $96 \mathrm{~h}$, then increased rapidly, and finally showed a slow increasing trend after the 192nd hour.

Based on the above changes, the SOM degradation process in this study could be mainly divided into three phases, i.e. aerobic (phase 1), aerobic-anaerobic (phase 2) and anaerobic degradation (phase 3 ). In the first phase, the SOC rates ranged from 2.34 to $6.03 \mathrm{mmol} \mathrm{m} \mathrm{m}^{-1}$ with the average of $4.02 \pm 1.29$ and $3.38 \pm 0.90 \mathrm{mmol} \mathrm{m}^{-2} \mathrm{~d}^{-1}$ for the samples from the MA and the NMA, respectively; in the second phase, the average of SOC rates were $1.06 \pm 0.72$ and $2.36 \pm 0.34 \mathrm{mmol} \mathrm{m}^{-2} \mathrm{~d}^{-1}$ for the samples from the MA and the NMA; while its values were $<0.50 \mathrm{mmol} \mathrm{m}^{-2}$ $\mathrm{d}^{-1}$ in the third phase.

In terms of DIC, the production rates in the first phase ranged from 3.32 to $8.41 \mathrm{mmol} \mathrm{m}^{-2} \mathrm{~d}^{-1}$ with the average of $6.05 \pm 1.58$ and $3.96 \pm 0.93 \mathrm{mmol} \mathrm{m}^{-2} \mathrm{~d}^{-1}$ for the samples from the MA and the NMA; however, the DIC production rates in the second phase were about 1-2 times higher than those in the first phase; in the third phase, the DIC production rates dropped to $3.67 \pm 3.95$ and $5.01 \pm 1.20 \mathrm{mmol} \mathrm{m}^{-2} \mathrm{~d}^{-1}$ for the samples from the MA and the NMA (Fig. 2d).

\subsection{Production rates of nutrients and FDOM}

\subsubsection{Inorganic nutrients}

As the incubation experiment progressed, the $\mathrm{NH}_{4}^{+} \mathrm{PO}_{4}^{3-}$ and $\mathrm{SiO}_{3}^{2-}$ concentrations in the overlying water showed an obvious increasing trend (Fig. 3). Generally, for the samples from the MA, the $\mathrm{NH}_{4}^{+}$concentrations stabilized after it rose to $\sim 130 \mu \mathrm{mol} \mathrm{l}{ }^{-1}$ in the first phase. In comparison, for the samples from the NMA, the growth rates of $\mathrm{NH}_{4}^{+}$concentrations were relatively slow, and the concentrations stabilized after reaching $\sim 120 \mu \mathrm{mol} \mathrm{l}^{-1}$ at the 144 th hour (Fig. 3c). For $\mathrm{PO}_{4}^{3-}$, its concentrations showed an obvious increasing trend from the second phase, reaching $3.17 \pm 0.43$ and $3.05 \pm 0.13 \mu \mathrm{mol} \mathrm{l}^{-1}$ at the 264 th hour for the samples from the MA and the NMA, respectively (Fig. 3d). The $\mathrm{SiO}_{3}^{2-}$ concentrations showed a significant increasing trend in the first two phases (Fig. 3e). In contrast, $\mathrm{NO}_{3}^{-}$concentrations showed significant downward trends in the first two phases, and stabilized after reaching $\sim 0.9 \mu \mathrm{mol} \mathrm{l}^{-1}$ at the 216 th hour, accounting for $\sim 30 \%$ of the initial concentrations for the samples from the MA and the NMA (Fig. 3a). However, the concentrations of $\mathrm{NO}_{2}^{-}$had no obvious changing trend during the experiment (Fig. 3b).

According to the above concentration variations, the production rates of $\mathrm{NH}_{4}^{+}, \mathrm{PO}_{4}^{3-}$ and $\mathrm{SiO}_{3}^{2-}$ for the samples from the MA and the NMA in different phases were calculated (Fig. 4). Overall, the $\mathrm{NH}_{4}^{+}$, $\mathrm{PO}_{4}^{3-}$ and $\mathrm{SiO}_{3}^{2-}$ fluxes measured in this study were within the range of most other reports in Table 1 . In detail, the $\mathrm{NH}_{4}^{+}$production was mainly in the first phase, and the production rates varied from 2.04 to $5.62 \mathrm{mmol} \mathrm{m}^{-2} \mathrm{~d}^{-1}$, with the mean values of $4.26 \pm 0.80$ and $2.50 \pm 0.42 \mathrm{mmol} \mathrm{m}^{-2} \mathrm{~d}^{-1}$ for the samples from the MA and the NMA. As for $\mathrm{PO}_{4}^{3-}$, the high production rates were in the second and third phases, ranging from 15.0 to $73.9 \mu \mathrm{mol} \mathrm{m} \mathrm{m}^{-2} \mathrm{~d}^{-1}$ with no significant difference between the samples from the MA and the NMA. In terms of $\mathrm{SiO}_{3}^{2-}$ production, it mainly occurred in the first two phases with the average of $1.80 \pm 0.48$ and $1.43 \pm 0.31 \mathrm{mmol} \mathrm{m}^{-2} \mathrm{~d}^{-1}$, respectively.
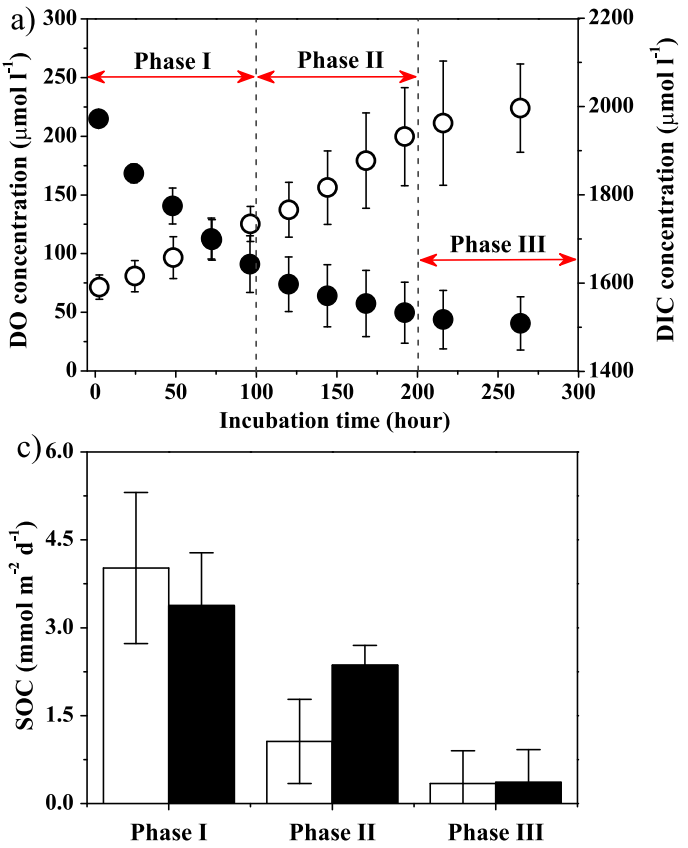
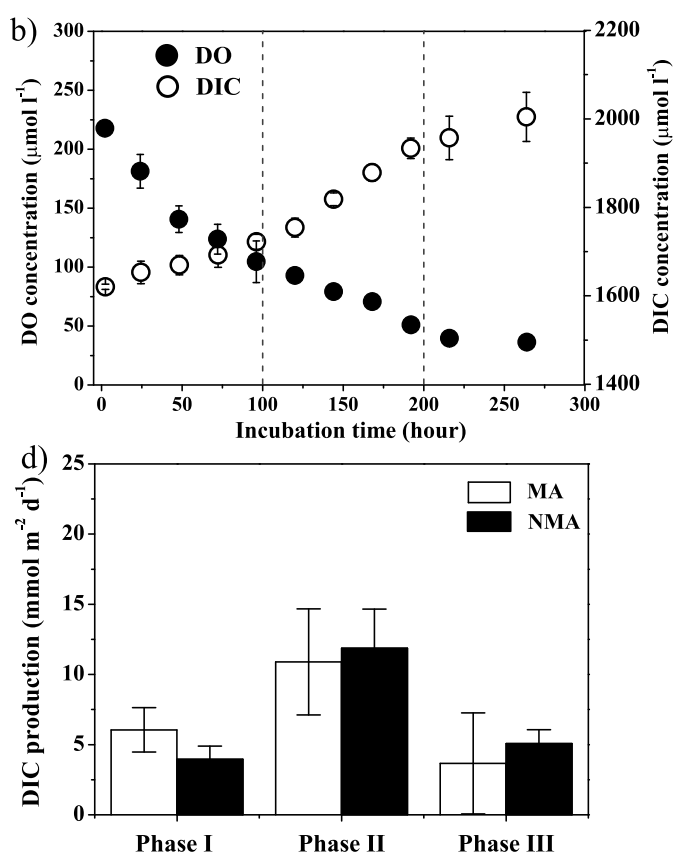

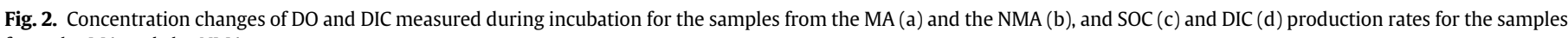
from the MA and the NMA. 

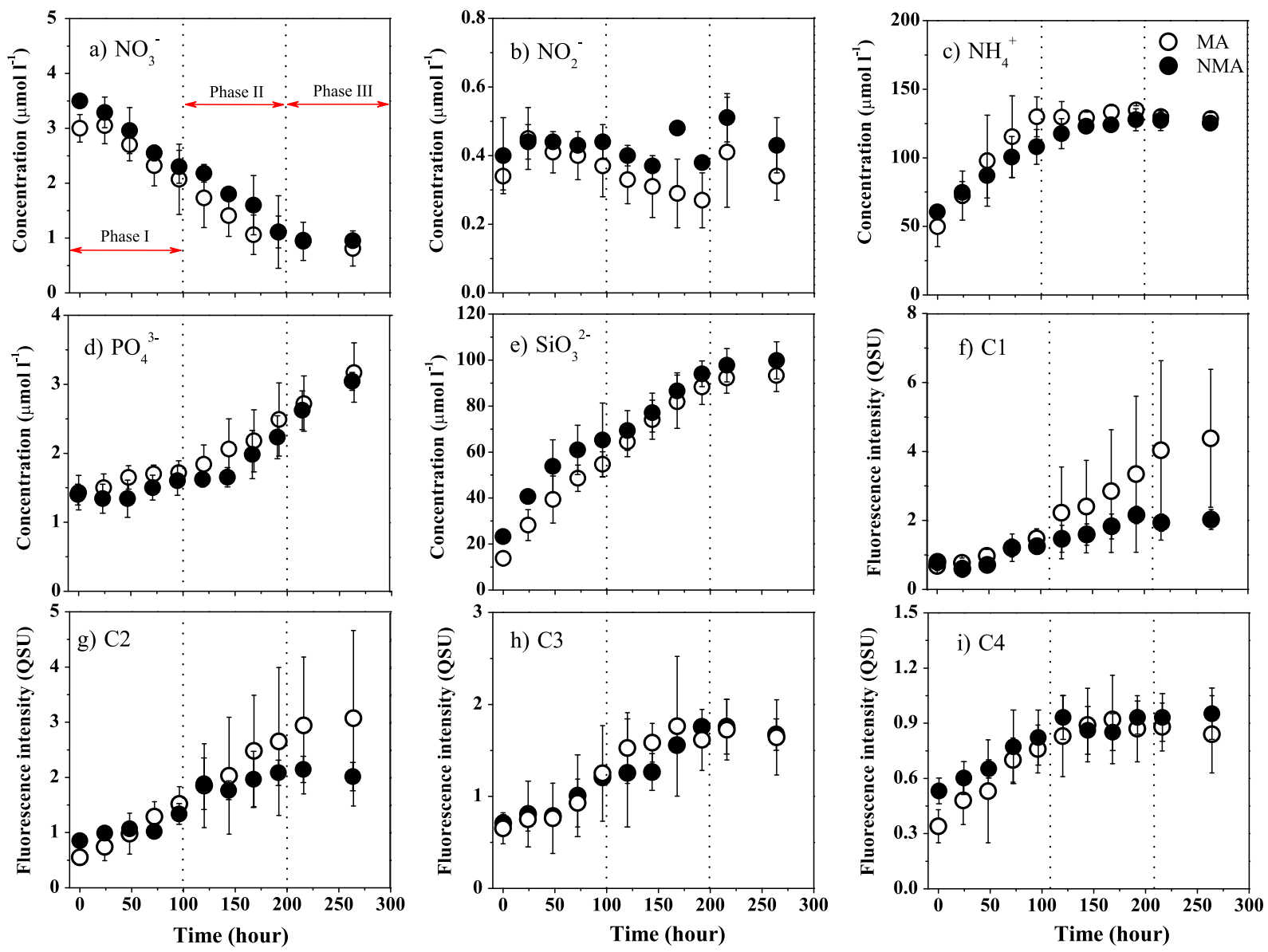

Fig. 3. Variation characteristics of inorganic nutrient concentration and fluorescent component intensity during incubation.
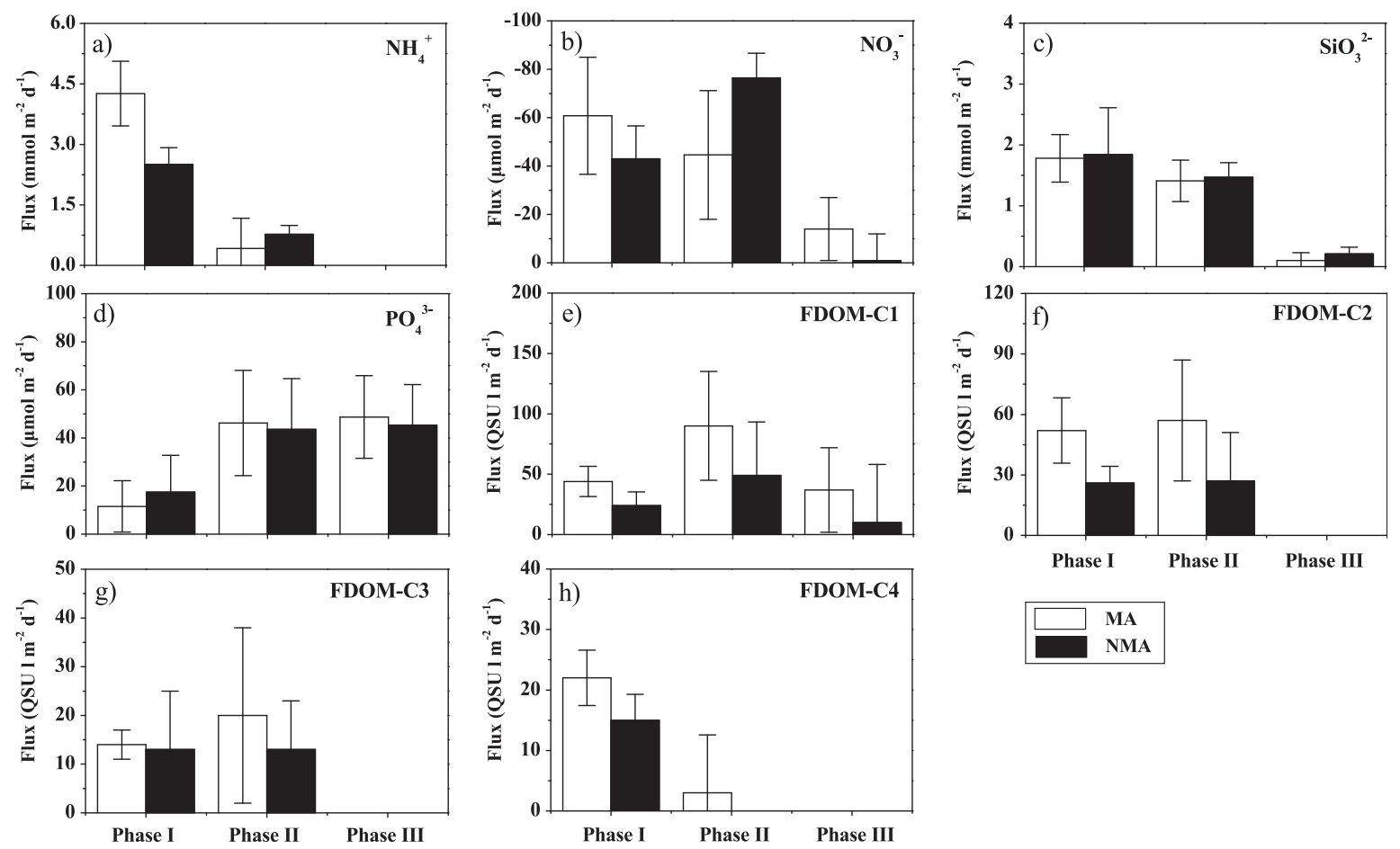

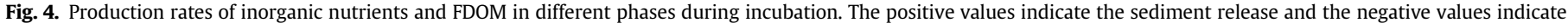
the sediment absorption. 
Table 1

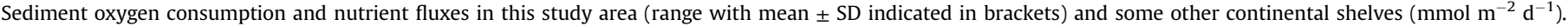
Positive values indicate the release of nutrient from sediment, and negative values indicate the absorption of nutrient by sediment.

\begin{tabular}{|c|c|c|c|c|c|c|c|}
\hline Location & Time & SOC & $\mathrm{NH}_{4}^{+}$ & $\mathrm{NO}_{3}^{-}$ & $\mathrm{PO}_{4}^{3-}$ & $\mathrm{SiO}_{3}^{2-}$ & References \\
\hline Gulf of Mexico & Aug. 2011 & 0.1 to 15.9 & 0 to 7.20 & -1.80 to 0.26 & 0.05 to 1.40 & 0.8 to 11.8 & William et al. (2019) \\
\hline Oregon continental shelf & 2009 & 1.1 to 9.8 & na & na & na & na & Reimers et al. (2012) \\
\hline Marian Cove, King George Island & 1995-2000 & 11.9 to 35.9 & 0.78 to 2.75 & -0.8 to 0.9 & na & 1.2 to 17.3 & Shim et al. (2011) \\
\hline Waquoit Bay estuarine & $2011-2013$ & 3.9 to 22.2 & -2.64 to 11.52 & na & na & 0 to 8.5 & Foster and Fulweiler (2019) \\
\hline Northern Gulf of Mexico & Jul.2008-May 2011 & 9.7 to 43.2 & na & na & na & na & Mccarthy et al. (2013) \\
\hline Area off eastern Taiwan & May 2014 & na & -0.11 to 0.22 & -0.24 to $<0.001$ & -0.11 to 0.034 & -0.55 to 0.040 & Zhou et al. (2017) \\
\hline Louisiana continental shelf & $2003-2007$ & 1.3 to 23.3 & na & na & na & na & Murrell and Lehrter (2011) \\
\hline Firth of Thames, New Zealand & $2003-2004$ & 20.7 to 73.9 & 1.92 to 7.66 & 0.07 to 0.52 & 0.01 to 0.60 & na & Giles and Pilditch (2006) \\
\hline Southern North Sea & $2007-2008$ & 1.1 to 15.1 & na & na & na & na & Neubacher et al. (2011) \\
\hline \multirow[t]{2}{*}{ Sanggou Bay } & May and Aug. 1999 & 15 to 24 & na & na & na & na & Zhang et al. (2006) \\
\hline & Jul. 2007 & na & 0.055 to 0.207 & 0.009 to 0.036 & 0.003 to 0.008 & 0.155 to 0.241 & Sun et al. (2010) \\
\hline Rushan Bay & 2009 & 35 & 0.106 to 0.238 & -0.027 to 0.018 & $<0.001$ & na & Zhao (2017) \\
\hline Northern coastal Tianjin, Bohai Bay & May 2012 & na & -0.46 & 1.76 & 0.012 & 2.56 & Mu et al. (2017) \\
\hline Changli coastal waters & $2015-2016$ & na & -0.21 to 3.81 & -0.12 to 0.32 & -0.018 to 0.02 & na & Hu et al. (2017) \\
\hline Yellow Sea & 2010 & 1.4 to 8.9 & na & na & na & na & Song et al. (2016) \\
\hline $\begin{array}{l}\text { Muping Marine Ranch and its } \\
\text { adjacent waters }\end{array}$ & Aug. 2017 & na & 0.216 to 0.347 & -0.318 to -0.174 & 0.021 to 0.097 & 0.92 to 1.44 & Gao (2019) \\
\hline \multirow{2}{*}{$\begin{array}{l}\text { Coastal waters around the Yangma } \\
\text { Island }\end{array}$} & Jul. 2017 & 2.34 to 6.03 & 2.04 to 5.62 & -0.097 to -0.024 & 0.015 to 0.074 & 1.22 to 2.71 & This study \\
\hline & & $(3.84 \pm 1.19)$ & $(3.78 \pm 1.07)$ & $(-0.056 \pm 0.023)$ & $(0.048 \pm 0.016)$ & $(1.80 \pm 0.48)$ & \\
\hline
\end{tabular}

na $=$ not available

\subsubsection{FDOM}

PARAFAC showed that, in this study, a four-component model was adapted for the data set (Fig. S2 and Table S3). Component C1 $(\mathrm{Ex} / \mathrm{Em}=275 / 320,340)$ was similar to marine protein-like or tryptophan-like substance; $\mathrm{C} 2(\mathrm{Ex} / \mathrm{Em}=315 / 395)$ was marine humic-like substances; $\mathrm{C} 3(\mathrm{Ex} / \mathrm{Em}=270 / 450)$ and $\mathrm{C} 4(\mathrm{Ex} /$ $\mathrm{Em}=365 / 450$ ) were humic-like substance (Table S3). The above components $(\mathrm{C} 1-\mathrm{C} 4)$ were all observed in the overlying water in July, which correspond to the components C1, C2 and C3 in seawater, respectively (Figs. S1 and S2).

During the incubation period, the fluorescence intensities of $\mathrm{C} 1-\mathrm{C} 4$ all showed an increasing trend (Fig. $3 \mathrm{f}-\mathrm{i}$ ). For components $\mathrm{C} 1-\mathrm{C} 3$, their intensities rose rapidly in the first two phases, and stabilized after the 216th hour. However, the intensity of C4 rose rapidly in the first phase, reaching $~ 0.9$ QSU at the 120th hour, then it slowed down afterwards.

For the production rates of the four identified FDOM components, their corresponding rates in the first phase were $38.0 \pm 15.1$, $45.2 \pm 18.5,14.5 \pm 12.1$ and $20.5 \pm 5.5$ QSU $1 \mathrm{~m}^{-2} \mathrm{~d}^{-1}$ for $\mathrm{C} 1$ to C4, respectively; the production rates for the samples from the MA were 1.9, 2.0, 1.1 and 1.5 times of these from the NMA (Fig. 4). In the second phase, the production rates of $\mathrm{C} 1-\mathrm{C} 3$ for the samples from the MA were $89.7 \pm 45.2,57.7 \pm 30.0$ and $20.0 \pm 20.2$ QSU $1 \mathrm{~m}^{-2} \mathrm{~d}^{-1}$. In comparison, the production rates of $\mathrm{C} 1$ and $\mathrm{C} 2$ for the samples from the MA were 2.0 and 2.1 times that of the samples from the NMA; however, the production rates of $\mathrm{C} 3$ for the samples from the MA and the NMA were almost equal.

\subsection{Correlation and principal component analysis}

Two principal components, i.e. PC1 and PC2, were distinguished, which explains $84.0 \%$ and $83.4 \%$ of the total variance for the samples from the MA and the NMA, respectively (Fig. 5). PC1 accounted for $71.2 \%$ and $73.8 \%$ of the total variance for the samples from the NMA and the MA, and had high positive loadings for FDOM components $\mathrm{C} 1-\mathrm{C} 4, \mathrm{NH}_{4}^{+}, \mathrm{PO}_{4}^{3-}$ and $\mathrm{SiO}_{3}^{2-}$ and negative loading for $\mathrm{DO}$ and $\mathrm{NO}_{3}^{-}$, reflecting the consumption of $\mathrm{DO}$ and the release of $\mathrm{NH}_{4}^{+}$, $\mathrm{PO}_{4}^{3-}, \mathrm{SiO}_{3}^{2-}$ and FDOM during the degradation of SOM; thus, there was a significant correlation between them for the samples from both the MA and the NMA (Table S4). PC2 accounted for $12.8 \%$ and
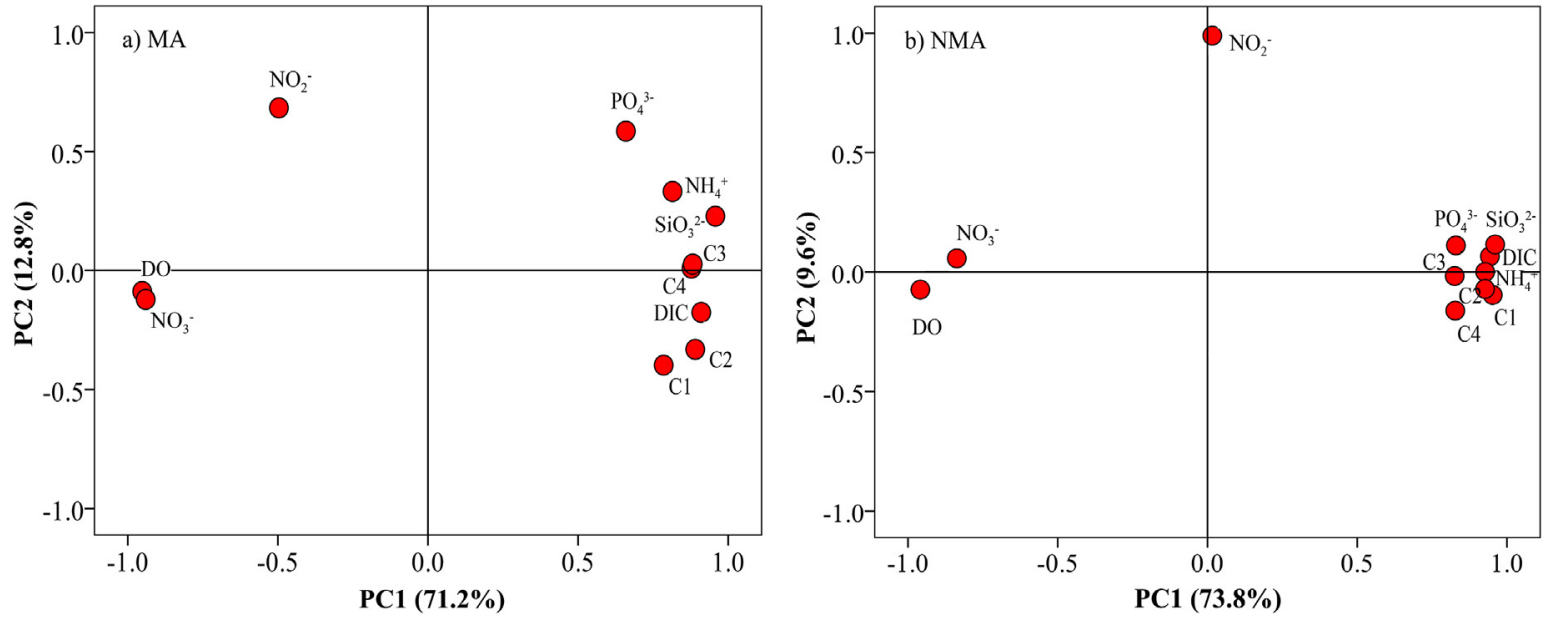

Fig. 5. PCA loadings for DIC, DO, inorganic nutrients and FDOM $(\mathrm{C} 1-\mathrm{C} 4)$ for the samples from the MA and the NMA during incubation. 
9.6\% of the total variance for the samples from the NMA and the MA with high positive loadings for $\mathrm{NO}_{2}^{-}$, indicating that SOM degradation had an effect on $\mathrm{NO}_{2}^{-}$production to some extent.

\section{Discussion}

\subsection{SOM degradation characteristics}

In this study, the results showed that the SOM degradation was mainly aerobic respiration in the first $96 \mathrm{~h}$. Overall, the SOC in the first phase agreed with that of the Yellow Sea (Song et al., 2016), but lower than those results of most coastal waters listed in Table 1. The SOC in the second and third phases was not compared with other sea areas because the chemical reactions in these phases might not represent those under natural conditions.

Previous studies have shown that scallop farming activities can significantly promote SOM accumulation in aquatic environment due to the high biological deposition (Liu et al., 2016), which can provide more substrates to microorganisms in sediments. This partly explains that the samples from the MA were associated with a higher SOC rate than those from the NMA. However, no significant correlation was observed between SOC and OC (and TN as well) when all the samples were taken into account $(P>0.05$; Table S5). This may be controlled by the difference in composition of SOM such as the variation in the ratio of biologically active and refractory $\mathrm{OM}$ in the study area. We speculated that the proportion of refractory OM to the SOM in the NMA was higher that in the MA, thereby affecting the correlation between SOM and SOC.

In addition, sediment type is generally an important factor affecting SOC. Some previous studies have shown that SOC was significantly higher in fine-grained sediments than that in coarsegrained sediments (Parr and Mason, 2004; Utley et al., 2008). However, most of the samples used in this study were of clay or silt sediment type, which limited the SOC comparison between different sediment types.

The concentration of DO in the overlying water was a main controlling factor in the variation of SOC, primarily through affecting the redox conditions in the sediment (Zhou et al., 2017; Foster and Fulweiler, 2019; Krueger et al., 2020). The results of this study indicated that it was beneficial to the aerobic decomposition of SOM when the overlying-water DO concentration was $>100 \mu \mathrm{mol} \mathrm{l}^{-1}$; however, SOM was mainly of anaerobic decomposition when DO concentration was $<50 \mu \mathrm{mol} \mathrm{l}^{-1}$ (Fig. 2).

It was reported that, generally, ORP has a significant positive correlation with DO in the environment when DO is $>15 \mu \mathrm{mol} \mathrm{l}^{-1}$ (Feng et al., 2016; Krueger et al., 2020); thus, DO is a good indicator of redox condition to a certain extent. In this study, although the ORP data in the sediments were not obtained during the incubation experiment, the dynamic characteristics of ORP in the experiments were initially estimated by fitting the relationship between the overlying-water DO and the sediment ORP surveyed in 2017 (Fig. S3). As shown in Fig. S3, the sediment ORP and the overlyingwater DO showed a significant linear positive correlation. According to the linear relationship between them in summer (July and August) $\left(\mathrm{ORP}=0.93 \mathrm{DO}-122.4, \mathrm{R}^{2}=0.606, P<0.001\right.$; Fig. S3), it could be calculated that, in the first phase of the incubation experiment, the ORP values in the sediments ranged from -34 to $82 \mathrm{mV}$ (weak-reduction to reduction). In the second and third phases, the ORP values varied from -76 to $-34 \mathrm{mV}$ and -86 to -76 $\mathrm{mV}$, respectively, which indicated a reduced state (Song et al., 1990). However, it should be noted that the overlying water sampled in the field survey for ORP determination was $\sim 100 \mathrm{~cm}$ away from the seabed, which was different from that of the incubation experiment. This may cause the uncertainty of the calculated results deviating from the actual situation, therefore they should be taken as auxiliary evidence.

According to previous studies, benthic OC mineralization rates could be estimated based on the relationship between oxygen $(\mathrm{O})$ and carbon (C), and the $\mathrm{O} / \mathrm{C}$ molar ratio of $0.8-1.2$ was reported during Redfieldian decomposition (Canfield et al., 1993; Glud, 2008; Song et al., 2016). In this study, a ratio of 1, which has been widely used in related studies in coastal waters (Giles et al., 2007), was used to calculate the mineralization rate of benthic OC. Accordingly, the average of benthic OC mineralization rates for the samples from the MA were $4.02 \pm 1.29$ and $1.06 \pm 0.72 \mathrm{mmol} \mathrm{m}^{-2}$ $\mathrm{d}^{-1}$ in the first and second phases. For the samples from the NMA, the benthic OC mineralization rates were $3.38 \pm 0.90$ and $2.36 \pm 0.34 \mathrm{mmol} \mathrm{m}^{-2} \mathrm{~d}^{-1}$, respectively.

\subsection{Linking SOM degradation to biogenic element cycle}

During incubation experiment, the $\mathrm{NO}_{3}^{-}, \mathrm{NH}_{4}^{+}, \mathrm{PO}_{4}^{3-}, \mathrm{SiO}_{3}^{2-}$ and FDOM (C1-C4) fluxes across the sediment-water interface were found to present obvious variations (Fig. 4). This indicated that the main processes regulating these biological elements may transform in different phases. Although the specific driving mechanism may not be clearly identified, the net fluxes measured in different phases can provide useful clues for subsequent analysis. Thus, the main processes behind the nutrient and FDOM fluxes in different phases was described below, i.e. the possible biochemical alterations at the sediment-water interface.

\subsubsection{Nutrient release}

Nutrient cycling processes have varying responses with SOM degradation at different phases. For DIN, $\mathrm{NH}_{4}^{+}$is usually the main form released from sediments, especially under low DO conditions, which are typically attributed to the increased $\mathrm{NH}_{4}^{+}$production by ammoniation (Foster and Fulweiler, 2019). As expected, it was observed that a large amount of $\mathrm{NH}_{4}^{+}$was released during the incubation process, while $\mathrm{NO}_{3}^{-}$showed an opposite trend, which has also been reported in previous studies (Matos et al., 2016; Zhou et al., 2017).

DO and $\mathrm{NH}_{4}^{+}$showed a significant negative correlation $(P<0.001)$ (Fig. $6 \mathrm{~d}$ and Table S4), indicating that ammoniation following ON decomposition might be an important process of consuming DO (Kim et al., 2020). However, the release of $\mathrm{NH}_{4}^{+}$ mainly occurred in the first phase of the culture period (aerobic degradation), after which it was not obvious. In addition, the ratio of SOC to DIN flux (SOC/DIN) was $\sim 1$ in the first phase, which was much lower than the theoretical SOC/DIN = 138:16 in SOM degradation (Redfield, 1958). This indicated that, besides SOM degradation, there were other processes of $\mathrm{NH}_{4}^{+}$release. During the field investigation, the DO concentration in the bottom water was relatively low in most sampling sites (Table S1), which could result in a large amount of $\mathrm{NH}_{4}^{+}$being stored in the sediment as a background component, thus, leading to a large release of this part of $\mathrm{NH}_{4}^{+}$during incubation via physical dissolution (Gao, 2019). In addition, the adsorption of sediments under reducing conditions $\left(\mathrm{DO}<100 \mu \mathrm{mol}^{-1}\right.$ ) may be the main reason for the insignificant change of $\mathrm{NH}_{4}^{+}$after the second phase.

For $\mathrm{PO}_{4}^{3-}$, its fluxes increased significantly after the second phase $\left(\mathrm{DO}<100 \mu \mathrm{mol} \mathrm{l}^{-1}\right.$ ) (Fig. 4), which was consistent with the results of other studies in coastal waters, e.g. the passing area of Kuroshio Current off eastern Taiwan (Zhou et al., 2017) and the Changjiang Estuary (Liu et al., 2020). The increase in $\mathrm{PO}_{4}^{3-}$ flux could be mainly caused by its release from the iron and manganese oxides and/or oxyhydroxides in the samples as the reducibility of the environment increases (Picard et al., 2019; Liu et al., 2020). The results of previous study indicated that $\mathrm{PO}_{4}^{3-}$ release from the sediments in this study area was mainly controlled by the 

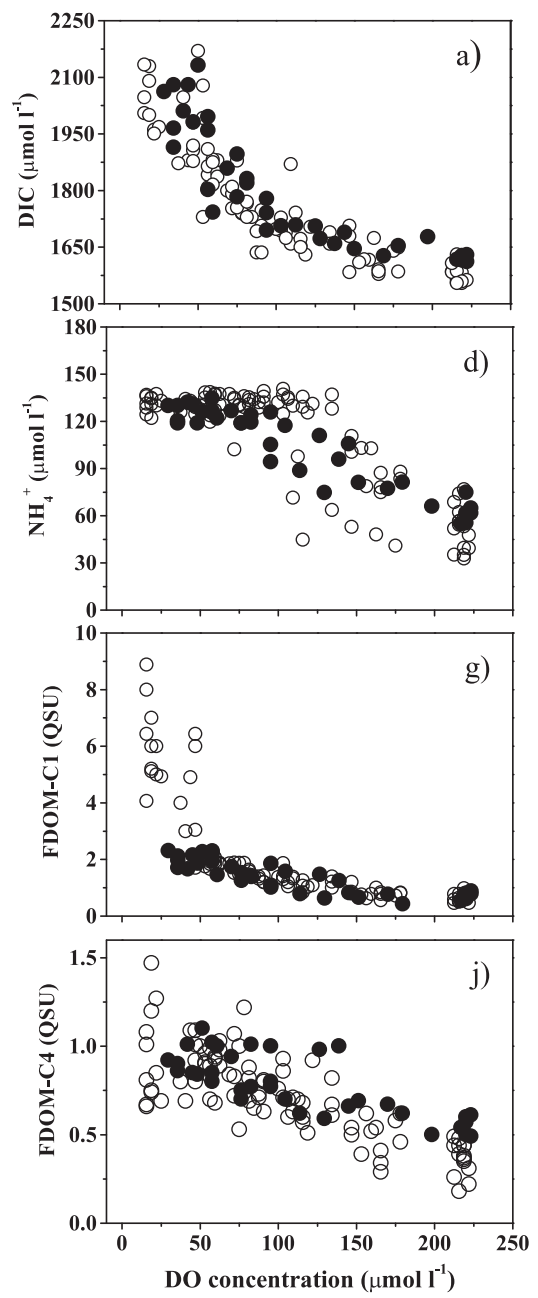
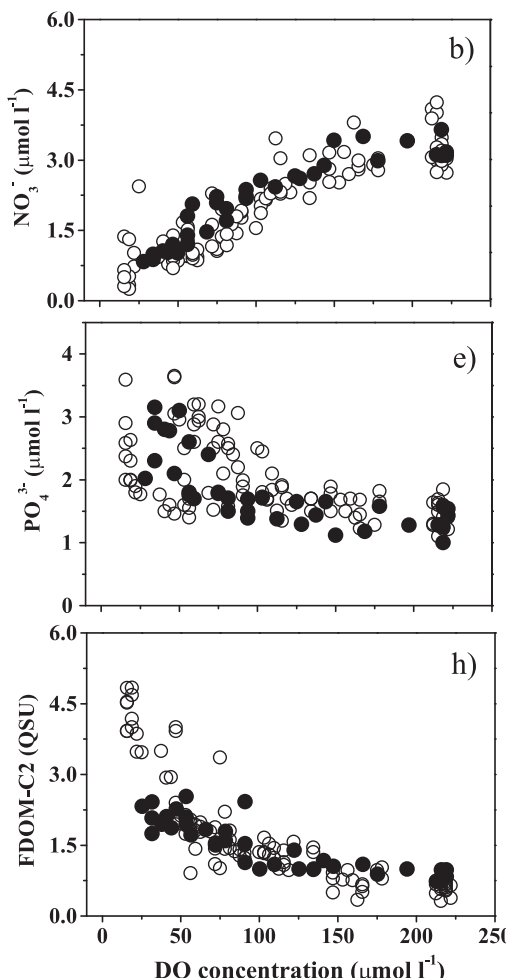

h)

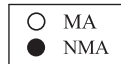

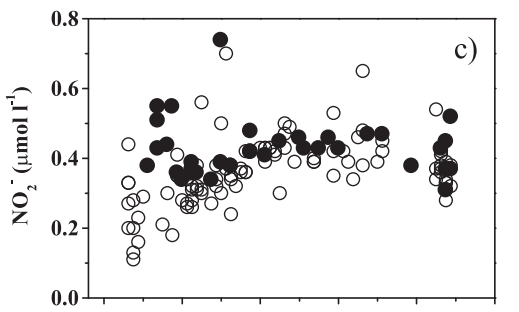
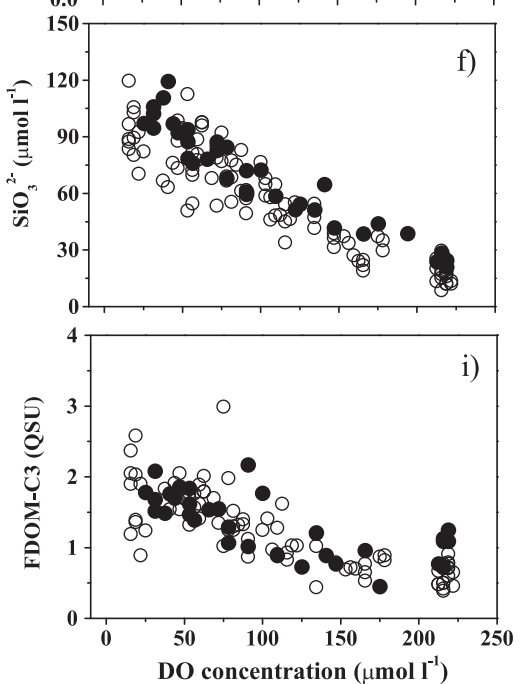

Fig. 6. Relationship between DO and DIC, inorganic nutrients and FDOM (C1-C4) for the samples from the MA and the NMA during incubation.

migration of iron-bound $\mathrm{P}$, organic $\mathrm{P}$ and exchangeable $\mathrm{P}$ (Yang et al., 2020b). Thus, in the first phase, $\mathrm{PO}_{4}^{3-}$ was mainly derived from the aerobic decomposition of SOM, which generally followed the equation of $\left(\mathrm{CH}_{2} \mathrm{O}\right)_{106}\left(\mathrm{NH}_{3}\right)_{16} \mathrm{H}_{3} \mathrm{PO}_{4}+1_{38 \mathrm{O}_{2}} \rightarrow$ $106 \mathrm{CO}_{2}+122 \mathrm{H}_{2} \mathrm{O}+16 \mathrm{HNO}_{3}+\mathrm{H}_{3} \mathrm{PO}_{4}$. In this process, $1 \mathrm{~mol} \mathrm{PO}_{4}^{3-}$ will be produced for every $138 \mathrm{~mol} \mathrm{O}_{2}$ consumed, i.e. $\triangle \mathrm{O}_{2}: \triangle \mathrm{PO}_{4}^{3-}=-138: 1$ (Redfield, 1958). However, the ratio of SOC to $\mathrm{PO}_{4}^{3-}$ flux ranged from 67 to 653 , with the average values of 298 for the samples from the MA and 193 for the samples from the NMA, which were significantly higher than the Redfield stoichiometry (Redfield, 1958; Glud, 2008). This may be controlled by the following factors. First of all, the environment in the first phase was in weak reducing condition; thus, the iron and manganese oxides and/or oxyhydroxides in the samples could effectively trap $\mathrm{PO}_{4}^{3-}$ released during SOM degradation. Secondly, during the degradation process, some of SOM was transformed into dissolved organic $P$ (DOP) rather than the final inorganic forms (Burdige et al., 2016; Zhao et al., 2018). After $120-144 \mathrm{~h}, \mathrm{PO}_{4}^{3-}$ could be mainly derived from the reduction release of $P$ combined with iron and manganese oxides and/or oxyhydroxides, and its flux was about 3-5 times that of the first phase (Fig. 4d).

The $\mathrm{SiO}_{3}^{2-}$ flux was generally related to the concentration of biogenic silica (Bio-Si) in sediment (Paudel et al., 2015). In the present study, overall, the release of $\mathrm{SiO}_{3}^{2-}$ from the samples may be related to the dissolution processes of Bio-Si, as observed with the high release fluxes in both anaerobic and aerobic conditions. Abe et al. (2014) reported that AOU increased with the increase of $\mathrm{SiO}_{3}^{2-}$ in the bottom water of the central Seto Inland. However, the results in this study showed that the effect of different DO conditions on $\mathrm{SiO}_{3}^{2-}$ flux was not obvious, indicating that $\mathrm{DO}$ might not be a main controlling factor for the release of $\mathrm{SiO}_{3}^{2-}$ from the sediment in this study area (Gao, 2019).

To clarify the contribution of the released DIN, $\mathrm{PO}_{4}^{3-}$ and $\mathrm{SiO}_{3}^{2-}$ from sediment to the phytoplankton's nutrient demand in this area in summer, the phytoplankton's demand on inorganic nutrients was estimated based on summer primary production rate, and the result was $\sim 6.63 \times 10^{4} \mu \mathrm{mol} \mathrm{m}{ }^{-2} \mathrm{~d}^{-1}$ in the study area (Gao, 2019), combined with the Redfield ratio i.e. C:N:Si:P = 106:16:16:1 (Redfield, 1958). The results showed that, for the studied samples, sediment $\mathrm{DIN}, \mathrm{PO}_{4}^{3-}$ and $\mathrm{SiO}_{3}^{2-}$ release could supply $37,2.4$ and $18 \%$ of the nutrient requirements of primary producers when the overlying-water DO concentration was $>100 \mu \mathrm{mol}^{-1}$ as that in the first phase of the incubation experiment. When the DO concentration was between 50 and $100 \mu \mathrm{mol} \mathrm{l}{ }^{-1}$ as that of in the second phase of the incubation experiment, the sediment could provide about $4.7,7.3$ and $14 \%$ of the phytoplankton's requirement of DIN, $\mathrm{PO}_{4}^{3-}$ and $\mathrm{SiO}_{3}^{2-}$. However, if the DO concentration was $<50 \mu \mathrm{mol} \mathrm{l}^{-1}$ as that of in the third phase of the incubation experiment, the sediment only provided a small amount of the DIN and $\mathrm{SiO}_{3}^{2-}$ required by phytoplankton, while the contribution of $\mathrm{PO}_{4}^{3-}$ maintained at $\sim 7.5 \%$. 


\subsubsection{FDOM production fluxes}

During the experiment, the DIC production rate in the second phase was about 2-3 times higher than that in the first phase (Fig. 2). The variation in DIC concentrations indicated that SOM degradation could be preferentially convert to DOM and further transform to DIC like that was reported in some previous studies (Komada et al., 2012; Burdige et al., 2016; Zhao et al., 2018). As expected, FDOM was produced in tandem with the degradation of SOM, especially in the first two phases. Thus, significant negative correlations between FDOM components $\mathrm{C} 1-\mathrm{C} 4$ and DO were observed $(P<0.001)$ (Fig. 6 and Table S4), suggesting the presence of a biological process for the production via respiration rather than physical pathway. The changes of the production rates along with the SOM degradation implied that there could be at least two mechanisms for the FDOM in situ production.

Generally, the benthic fluxes of FDOM could be influenced by a number of factors, e.g. redox condition, $\mathrm{pH}$ and temperature (Skoog et al., 1996; Kim and Kim, 2016). In an oxidizing and/or weak reducing environment, some FDOM can co-precipitate with $\mathrm{Fe}(\mathrm{III})$, while followed by the release of FDOM upon reduction of Fe(III) to $\mathrm{Fe}$ (II) under reducing conditions (Skoog et al., 1996). Therefore, the variations in DO concentrations in the overlying water could partially control FDOM flux, which might be the main reason for relatively high production rates of marine protein-like or tryptophan-like component $\mathrm{C} 1$, marine humic-like component $\mathrm{C} 2$ and humic-like component $\mathrm{C} 3$ occurred in the second phase (Fig. 4). However, the production of humic-like component C4 mainly occurred in the first phase of the experiment, indicating that C4 could be mainly derive from aerobic degradation of SOM (Guo et al., 2011; Yang and Gao, 2019).

In July 2017, the mean fluorescence intensities of marine protein-like or tryptophan-like, marine humic-like and humic-like components in the overlying water $(\sim 1 \mathrm{~m}$ above the seabed) were $0.365,0.276$ and 0.213 QSU, respectively, in the coastal waters around the Yangma Island (Table S1). Thus, the contributions of produced tryptophan-like, marine humic-like and humic-like components by SOM degradation in the first phase were estimated to be 10,16 and $7 \%$ of the overlying water in one day, and the corresponding values in the second phase were 20,18 and $9 \%$. Therefore, the decomposition of SOM could be an important source of FDOM in the overlying water in this study area.

\subsection{Implications and deficiencies}

This study demonstrated that, affected by the biological deposits of scallops, the SOC rate for the samples from the MA was significantly higher than that for the samples from the NMA, suggesting the potential connection between intensive mariculture and the loss of DO in water. As what was well known, in recent years, seasonal low-oxygen/hypoxic events have occurred frequently in the coastal areas of China, e.g. the Yangtze River Estuary and the Pearl River Estuary (Zhu et al., 2015; Qian et al., 2018; Jenny and Jill, 2020), which has brought huge economic losses. Thus, the exploration of the mechanism of hypoxia and making effective strategies to reduce the damage caused by hypoxia are quite necessary in the future for keeping good quality of coastal environments and sustainable mariculture development.

In addition, this research showed that, with the change of the overlying-water DO concentration, the migration and transformation behavior of biogenic elements at the sediment-water interface has varied significantly due to the changes in degradation mode of SOM, i.e. aerobic and anaerobic degradation. Generally, when DO $>50 \mu \mathrm{mol} \mathrm{l}^{-1}$, it was beneficial to the release of $\mathrm{NH}_{4}^{+}$, $\mathrm{SiO}_{3}^{2-}$ and FDOM. In contrast, low oxygen conditions, i.e. $\mathrm{DO}<100 \mu \mathrm{mol} \mathrm{l}{ }^{-1}$, stimulated sediment $\mathrm{PO}_{4}^{3-}$ efflux. Although the experimental results may be different from the actual situation, this research highlight the important role of SOM degradation processes and their contribution to energy and matter cycling in coastal waters, especially mariculture areas. In-depth research on the topic of this study is a key step for the prediction of benthic processes and is beneficial for the evaluation and management of coastal ecosystem services.

In this research, only a small part of the biogeochemical parameters that related to sediment degradation was concerned. The degradation process of SOM will also promote the release of other harmful matter, such as heavy metals, hydrogen sulfide $\left(\mathrm{H}_{2} \mathrm{~S}\right)$ and $\mathrm{CH}_{4}$. All of these will have adverse effects on maraculture ecosystems, which need further research. Besides, this research still has other obvious flaws, especially in the sample selection. The samples used in this study were from the MA and the NMA, respectively. The latter was relatively far from the coast than the former. Therefore, in addition to the mariculture, other factors, e.g. terrestrial input, hydrodynamic conditions, and the exchange process with the outer waters, may also potentially cause differences in the results of the two groups of samples. Therefore, additional studies for this area are necessary in the future to solve/perfect the above-mentioned potential problems/flaws.

\section{Conclusions}

This research aimed to study the biogeochemical processes of biogenic elements in the water-sediment interface switching from being oxic to hypoxic by microbial respiration in a scallop culture area. According to the changes in DO concentration during the incubation process, the sediment mineralization process can be divided into three phases, namely aerobic (DO $>100 \mu \mathrm{mol} \mathrm{l}^{-1}$ ), aerobic-anaerobic $\left(50<\mathrm{DO}<100 \mu \mathrm{mol} \mathrm{l}^{-1}\right)$ and anaerobic $\left(\mathrm{DO}<50 \mu \mathrm{mol}^{-1}\right.$ ) degradations. Compared with some coastal areas, the SOC of this study was relatively low in summer. In different mineralization processes, the release flux rates of nutrients and FDOM from sediment were estimated and it was found that the results changed significantly for $\mathrm{NH}_{4}^{+}, \mathrm{SiO}_{3}^{2-}, \mathrm{PO}_{4}^{3-}$ and FDOM. When DO $>50 \mu \mathrm{mol} \mathrm{l}^{-1}$, it was beneficial to the release of $\mathrm{NH}_{4}^{+}, \mathrm{SiO}_{3}^{2-}$ and FDOM. In contrast, low oxygen condition with DO $<100 \mu \mathrm{mol} \mathrm{l}^{-1}$ stimulated the sediment phosphate efflux. In addition, the results indicated that $\mathrm{SOC}$ and the fluxes of $\mathrm{NH}_{4}^{+}$and FDOM across the sediment-water interface in the MA were higher than those in the NMA. This might be partially owning to the fact that the sediments in the scallop farming area had a higher amount of SOM affected by the scallop excretion of feces, pseudofeces and so on, which provided more substrates to microorganisms in sediments, thereby accelerating the SOC and benthic fluxes of nutrient and FDOM. This study highlighted the significant effects of DO availability and mariculture on the biogeochemisty of biogenic elements in the sedimentary environment.

\section{Credit author statement}

Bo Yang: Investigation, Formal analysis, Writing - original draft; Xuelu Gao: Conceptualization, Resources, Writing - review \& editing; Jianmin Zhao: Funding acquisition, Writing - review \& editing; Yongliang Liu, Lei Xie, Xiaoqing Lv \& Qianguo Xing: Writing - review \& editing.

\section{Declaration of competing interest}

The authors declare that they have no known competing financial interests or personal relationships that could have appeared to influence the work reported in this paper. 


\section{Acknowledgments}

This work was financially supported by the Strategic Priority Research Program of the Chinese Academy of Sciences (XDA23050303).

\section{Appendix A. Supplementary data}

Supplementary data to this article can be found online at https://doi.org/10.1016/j.chemosphere.2021.129641.

\section{References}

Abe, K., Nakagawa, N., Abo, K., Tsujino, M., 2014. Dissolution of silica accompanied by oxygen consumption in the bottom layer of Japan's central Seto Inland Sea in summer. J. Oceanogr. 70, 267-276.

Burdige, D.J., Komada, T., Magen, C., Chanton, J.P., 2016. Modeling studies of dissolved organic matter cycling in Santa Barbara Basin (CA, USA) sediments. Geochem. Cosmochim. Acta 195, 100-119.

Cai, W.J., Dai, M.H., Wang, Y.C., Zhai, W.D., Huang, T., Chen, S.T., 2004. The biogeochemistry of inorganic carbon and nutrients in the Pearl River estuary and the adjacent Northern South China Sea. Continent. Shelf Res. 24 (12), 1301-1319.

Canfield, D.E., Jørgensen, B.B., Fossing, H., Glud, R.N., Gundersen, J.K., Ramsing, N.B., Thamdrup, B., Hansen, J.W., Nielsen, N.P., Hall, P.O.J., 1993. Pathways of organic carbon oxidation in three continental margin sediments. Mar. Geol. 113, 27-40.

Daniele, N., Marco, B., Pierluigi, V., 2006. Nitrogen and phosphorous budgets during a farming cycle of the Manila clam Ruditapes philippinarum: an in situ experiment. Aquaculture 261 (1), 98-108.

Derrien, M., Shin, K.H., Hur, J., 2019. Biodegradation-induced signatures in sediment pore water dissolved organic matter: implications from artificial sediments composed of two contrasting sources. Sci. Total Environ. 694, 133714.

FAO, 2016. The State of World Fisheries and Aquaculture 2016. Food and Agriculture Organization of the United Nations, Rome, pp. 1-200.

Feng, W.H., Wang, Z.F., Zhang, R.B., Zhang, D.R., Ye, M.S., Chen, D.H., 2016. The environment characteristics of redox in the surface sediments of Ningde coastal sea area in relation to influence factors. Mar. Environ. Sci. 6, 883-887.

Foster, S.Q., Fulweiler, R.W., 2019. Estuarine sediments exhibit dynamic and variable biogeochemical responses to hypoxia. J. Geophys. Res. 124 (4), 737-758.

Gan, S., Schmidt, F., Heuer, V.B., Goldhammer, T., Hinrichs, K.U., 2020. Impacts of redox conditions on dissolved organic matter (DOM) quality in marine sediments off the River Rhône, Western Mediterranean Sea. Geochem. Cosmochim. Acta 276, 151-169.

Gao, T.C., 2019. Exchange Fluxes of Nutrients across Sediment-water Interface in the Muping Marine Ranch and its Adjacent Waters. M.S. Thesis, University of Chinese Academy of Sciences, Beijing, China, p. 97.

Giles, C.A., Pilditch, D.G., 2006. Sedimentation from mussel (Perna canaliculus) culture in the Firth of Thames, New Zealand: impacts on sediment oxygen and nutrient fluxes. Aquaculture 261 (1), 125-140.

Giles, H., Pilditch, C.A., Nodder, S.D., Zeldis, J.R., Currie, K., 2007. Benthic oxygen fluxes and sediment properties on the northeastern New Zealand continental shelf. Continent. Shelf Res. 27, 2373-2388.

Glud, R.N., 2008. Oxygen dynamics of marine sediments. Mar. Biol. Res. 4, 243-289.

Guo, W.D., Yang, L.Y., Hong, H.S., 2011. Assessing the dynamics of chromophoric dissolved organic matter in a subtropical estuary using parallel factor analysis. Mar. Chem. 124, 125-133.

Hantush, M.M., 2007. Modeling nitrogen-carbon cycling and oxygen consumption in bottom sediments. Adv. Water Resour. 30 (1), 59-79.

Hu, B., Tan, L.J., Wang, J.T., 2017. Study on the diffusion fluxes of dissolved inorganic nitrogen phosphorus and urea across sediment-water interface in scallop culture area of Changli coastal waters. Mar. Environ. Sci. 36 (6), 864-870.

Huang, Q., Olenin, S., Jiang, T., Sun, S., De Troch, M., 2018. Assessing environmental effects of the bay scallop Argopecten irradians culture in China: using abiotic and biotic indicators. Aquaculture 499, 316-328.

Jenny, C.Y., Jill, M.Y., 2020. Changes in biofilm bacterial communities in response to combined effects of hypoxia, ocean acidification and nutrients from aquaculture activity in Three Fathoms Cove. Mar. Pollut. Bull. 156, 111256.

Kim, J., Kim, G., 2016. Significant anaerobic production of fluorescent dissolved organic matter in the deep East Sea (Sea of Japan). J. Geophys. Res. 43, 7609-7616.

Kim, S.H., Lee, J.S., Kim, K.T., Kim, S.L., Kim, S.H., 2020. Low benthic mineralization and nutrient fluxes in the continental shelf sediment of the northern East China Sea. J. Sea Res. 101934

Komada, T., Polly, J.A., Johnson, L., 2012. Transformations of carbon in anoxic marine sediments: implications from $\delta^{14} \mathrm{C}$ and $\delta^{13} \mathrm{C}$ signatures. Limnol. Oceanogr. 57, 567-581.

Krueger, K.M., Vavrus, C.E., Lofton, M.E., Mcclure, R.P., Schreiber, M.E., 2020. Iron and manganese fluxes across the sediment-water interface in a drinking water reservoir. Water Res. 182, 116003.

Lee, Y.G., Jeong, D.U., Lee, J.g., Sick, C., Yang, H., Lee, M.O., 2016. Effects of hypoxia caused by mussel farming on benthic foraminifera in semi-closed Gamak Bay, South Korea. Mar. Pollut. Bull. 109 (1), 566-581.
Liu, J., Krom, M.D., Ran, X., Zang, J., Liu, J., Yao, Q., Yu, Z., 2020. Sedimentary phosphorus cycling and budget in the seasonally hypoxic coastal area of Changjiang Estuary. Sci. Total Environ. 713 (15), 136389.

Liu, S., Peng, X., 2019. Organic matter diagenesis in hadal setting: insights from the pore-water geochemistry of the Mariana Trench sediments. Deep-Sea Res. Pt. $147,22-31$.

Liu, J., Zang, J., Zhao, C., Yu, Z., Xu, B., Li, J., Ran, X., 2016. Phosphorus speciation, transformation, and preservation in the coastal area of Rushan Bay. Sci. Total Environ. 565, 258-270.

Matos, R.L., Mendoza, U., Diaz, R., Moreira, M., Belem, A.L., Metzger, E., 2016. Nutrient regeneration susceptibility under contrasting sedimentary conditions from the Rio de Janeiro coast, Brazil. Mar. Pollut. Bull. 108 (1-2), 297-302.

Mccarthy, M.J., Carini, S.A., Liu, Z., Ostrom, N.E., Gardner, W.S., 2013. Oxygen consumption in the water column and sediments of the northern Gulf of Mexico hypoxic zone. Estuar. Coast Shelf Sci. 123, 46-53.

Mu, D., Yuan, D.F., Feng, H., Xing, F.W., Teo, F.Y., Li, S.Z., 2017. Nutrient fluxes across sediment-water interface in Bohai bay coastal zone, China. Mar. Pollut. Bull. 114 (2), 705-712

Murrell, M.C., Lehrter, J.C., 2011. Sediment and lower water column oxygen consumption in the seasonally hypoxic region of the Louisiana continental shelf. Estuar. Coast 34 (5), 912-924.

Neubacher, E.C., Parker, R.E., Trimmer, M., 2011. Short-term hypoxia alters the balance of the nitrogen cycle in coastal sediments. Limnol. Oceanogr. 56 (2), 651-665.

Parr, L.B., Mason, C.F., 2004. Causes of low oxygen in a lowland, regulated eutrophic river in Eastern England. Sci. Total Environ. 321 (1/3), 273-286.

Paudel, B., Montagna, P.A., Adams, L., 2015. Variations in the release of silicate and orthophosphate along a salinity gradient: do sediment composition and physical forcing have roles? Estuar. Coast Shelf Sci. 157, 42-50.

Picard, A., Gartman, A., Cosmidis, J., Obst, M., Girguis, P.R., 2019. Authigenic metastable iron sulfide minerals preserve microbial organic carbon in anoxic environments. Chem. Geol. 530, 119343.

Qian, W., Gan, J., Liu, J., He, B., Dai, M., 2018. Current status of emerging hypoxia in a eutrophic estuary: the lower reach of the pearl river estuary, China. Estuar. Coast Shelf Sci. 205, 58-67.

Redfield, A.C., 1958. The biological control of chemical factors in the environment Am. Sci. 46 (3), 230A-221.

Reimers, C.E., Özkan-Haller, H., Berg, P., Devol, A., 2012. Benthic oxygen consumption rates during hypoxic conditions on the Oregon continental shelf: evaluation of the eddy correlation method. J. Geophys. Res. 117 (C2), 1-18.

Rysgaard, S., Glud, R.N., Risgaard-Petersen, N., Dalsgaard, T., 2004. Denitrification and anammox activity in Arctic marine sediments. Limnol. Oceanogr. 49, 1493-1502.

Shim, J.G., Kang, Y.C., Kang, D.J., Han, M.W., 2011. Fluxes and budgets of biogenic elements at the sediment-water interface of marian cove, king George Island. Antarct. Sci. 23, 358-368, 04.

Skoog, A., Hall, P.O.J., Hulth, S., Paxéus, N., Loeff, M.R.V.D., Westerlund, S., 1996. Early diagenetic production and sediment-water exchange of fluorescent dissolved organic matter in the coastal environment. Geochem. Cosmochim. Acta 60 (19), 3619-3629.

Song, G., Liu, S., Zhu, Z., Zhai, W., Zhu, C., Zhang, J., 2016. Sediment oxygen consumption and benthic organic carbon mineralization on the continental shelves of the East China Sea and the Yellow Sea. Deep-Sea Res. Pt II 53-63.

Song, J.M., Li, D., Zhu, Z.B., 1990. Relationship between Eh value and the redox environment in marine sediments. Mar. Sci. Bull. 9 (4), 34-38.

Sun, S., Liu, S.M., Ren, J.L., Zhang, J.H., Jiang, Z.J., 2010. Distribution features of nutrients and flux across the sediment-water interface in the Sanggou Bay. Acta Oceanol. Sin. 32 (6), 108-117.

Tang, C., Li, Y., He, C., Acharya, K., 2020. Dynamic behavior of sediment resuspension and nutrients release in the shallow and wind-exposed Meiliang Bay of Lake Taihu. Sci. Total Environ. 708 (15), 135131.

Utley, B.C., Vellidis, G., Lowrance, R., Smith, M.C., 2008. Factors affecting sediment oxygen demand dynamics in blackwater streams of Georgia's coastal plain. J. Am. Water Resour. Assoc. 44 (3), 742-753.

Valérie, M., Ogier, S., Bally, G., Disnar, J.R., Lottier, N., Dedieu, K., 2007. Nutrient dynamics at the sediment-water interface in a Mediterranean lagoon (Thau, France): influence of biodeposition by shellfish farming activities. Mar. Environ. Res. 63 (3), 257-277.

Van Broekhoven, W., Troost, K., Jansen, H., Smaal, A. 2014. Nutrient regeneration by mussel Mytilus edulis spat assemblages in a macrotidal system. J. Sea Res. 88, 36-46.

William, M.B., James, M.M., Silke, S., Nick, R., 2019. Benthic fluxes from hypoxiainfluenced Gulf of Mexico sediments: impact on bottom water acidification. Mar. Chem. 209, 94-106.

Xia, B., Han, Q., Chen, B., Sui, Q., Jiang, T., Sun, X., 2019. Influence of shellfish biodeposition on coastal sedimentary organic matter: a case study from Sanggou Bay, China. Continent. Shelf Res. 172, 12-21.

Yang, B., Gao, X., 2019. Chromophoric dissolved organic matter in summer in a coastal mariculture region of northern Shandong Peninsula, North Yellow Sea. Continent. Shelf Res. 176, 19-35.

Yang, B., Gao, X., Xing, Q., 2018. Geochemistry of organic carbon in surface sediments of a summer hypoxic region in the coastal waters of northern Shandong Peninsula. Continent. Shelf Res. 171, 113-125.

Yang, B., Gao, X., Zhao, J., Lu, Y., Gao, T., 2020a. Biogeochemistry of dissolved inorganic nutrients in an oligotrophic coastal mariculture region of the northern 
Shandong Peninsula, north Yellow Sea. Mar. Pollut. Bull. 150, 110693.

Yang, B., Gao, X., Zhao, J. Liu, Y.L., Gao, T.C., Lui, H.K., Huang, T.H., Arthur Chen, C.T., Xing, Q.G., 2020b. The influence of summer hypoxia on sedimentary phosphorus biogeochemistry in a coastal scallop farming area, North Yellow Sea. Sci. Total Environ. 11, 143486.

Zhang, X., Zhu, M., Chen, S., 2006. Study on sediment oxygen consumption rate in the Sanggou bay and Jiaozhou bay. Adv. Mar. Sci. 24 (1), 91-96.

Zhao, B., Peng, Y., Bianchi, T.S., Arellano, A.R., Xuchen, W., Jianbin, Y., 2018. The remineralization of sedimentary organic carbon in different sedimentary regimes of the Yellow and East China Seas. Chem. Geol. 495, 104-117.
Zhao, Y.C., 2017. Controlling Processes of Dissolved Oxygen, Organic Carbon, Nitrogen and Phosphorus Cycles and Budgets in the Coastal Area of Rushan Bay and Bohai and Yellow Seas. M.S. Thesis. The First Institute of Oceanography, MNR, China, p. 140.

Zhou, F., Gao, X., Zhang, Y., Yuan, H., Song, J., Liu, K., Yang, B., 2017. Potential mobility of inorganic nutrients and its controls at the sediment-water interface in the main path of Kuroshio Current off eastern Taiwan. Mar. Pollut. Bull. 119 (1), $270-276$.

Zhu, J., Zhu, Z., Lin, J., Wu, H., Zhang, J., 2015. Distribution of hypoxia and pycnocline off the Changjiang estuary, China. J. Mar. Syst. 154, 28-40. 